\title{
PENGGUNAAN MEDIA FILM DALAM MENINGKATKAN KOMPETENSI PRAGMATIK MAHASISWA PRODI BAHASA INGGRIS UNIVERSITAS KANJURUHAN MALANG
}

\author{
Salwa \\ wawa.live@yahoo.co.id \\ Widya Hanum Sari P \\ hanoems@gmail.com \\ Universitas Kanjuruhan Malang
}

\begin{abstract}
Abstrak
Penelitian ini bertujuan untuk menciptakan strategi pembelajaran yang lebih menarik dengan menggunakan media film sebagai materi (supplementary materials) selain buku ajar untuk meningkatkan kompetensi pragmatik mahasiswa.penelitian ini diharapkan agar Ilmu Pragmatik dapat diajarkan dengan menggunakan film sebagai gambaran nyata dari penggunaan bahasa Inggris asli, baik verbal maupun non-verbali, diharapkan akan meningkatkan kompetensi pragmatik bagi mahasiswa.Mahasiswa juga diharapkanakan mampu menggunakan kalimat (discourse) yang sesuai dalam situasi komunikasi yang berbeda-beda. Dengan menggunakan materi otentik seperti film,diharapkan dapat membantu menaikkan tingkat pemahaman mahasiswa akan pentingnya kompetensi pragmatik khususnya dalam menunjang komunikasi efektif melalui para penutur bahasa Inggris asli tersebut.Juga untuk pengajar, akan terbantu dengan adanya hasil penelitian inidalam memasukkan aspek pragmatik yang terintegrasi dalam pengajaran bahasa Inggris melalui media film. Metode dalam penelitian ini adalah experimental design dengan menggunakan non-randomized control group, pretest-post-test design. Metode pengumpulan data yang dilakukan adalah melalui observasi, interview dan kuesioner. Dari hasil lima kali treatment yang di lakukan pada experimental group, terdapat kenaikan skor pada post-test. Dari hasil penelitian ini dapat disimpulkan bahwa penggunaan film dapat meningkatkan kompetensi Pragmatik para mahasiswa serta juga meningkatkan motivasi belajar mahasiswa dalam mempelajari ilmu Pragmatik.
\end{abstract}

\section{Kata Kunci :Kompetensi Pragmatik, media film, Communicative Competence}

Bahasa merupakan alat komunikasi yang mempunyai peranan sangat penting dalam interaksi antar manusia, sebagai alat untuk menyampaikan gagasan, ide dan keinginan kepada orang lain.

Dalam konteks pembelajaran bahasa Inggris sebagai bahasa asing di Indonesia, kebutuhan akan kompetensi linguistik seperti tata bahasa, semantik dan sintaksis saja tidak cukup. Karena bahasa yang di ucapkan seseorang akan dapat dipahami maknanya melalui konteks.Karena itulah sangat diperlukan kompetensi pragmatik, yaitu kemampuan untuk memahami makna dari lawan bicara kita yang fungsinya adalah untuk menghindari adanya kesalahfahaman serta makna yang ambigu ( mempunyai dua arti).

Hymes (1972,dalam Toyyibah, 2013) menyatakan, bahwa bahasa adalah sebuah bentuk tingkah laku sosial.Karena itu agar pembelajar bahasa dapat memiliki kompetensi komunikatif dalam berbicara, iajuga harus memahami tindak tutur dan tingkah laku dari para penutur asli bahasa tersebut.Karena jika pembelajar bahasa mempunyai kompetensi linguistic seperti tata bahasa (grammar) dan pengucapan (pronunciation) yang benar, tetapi tidak memiliki kompetensi pragmatik, maka akan terjadi kesalahfahaman atau diistilahkan dengan "Pragmatic Failure" ( kegagalan pragmatik).

Salah satu penyebab terjadinya kegagalan pragmatik adalah siswa mentransfer aturan pragmatik di bahasa pertama mereka ( dalam hal ini bahasa Indonesia) kedalam bahasa asing yang sedang mereka pelajari ( Thomas, 1983 dalam Grossi, 2009). 
Yang menarik, beberapa penelitian di bidang pengajaran bahasa Inggris sebagai bahasa asing atau English as a Foreign Language( $E F L$ ), terdapat perdebatan, apakah ilmu pragmatik perlu diajarkan dalam proses pembelajaran bahasa asing? beberapa ahli berpendapat bahwa keahlian pragmatik dapat diperoleh secara otodidak dengan seringnya mahasiswa mempelajari bahasa Inggris, tetapi banyak penelitian di lapangan membuktikan bahwasanya kompetensi pragmatik akan meningkat apabila pengajar memberikan instruksi ekplisit (explicit instructions) dalam pragmatik seperti film dan novel.

Brock (2005) dan Soler (2008) juga menambahkan, pengajar bahasa asing seharusnya memberi banyak aktifitas menarik di dalam kelas untuk mempelajari secara mendalam tentang pragmatik dan perbedaan sosial budaya yang dapat dipelajari melalui bahasa baik secara verbal maupun non-verbal (bahasa tubuh, intonasi, ekspresi wajah). Penemuan dari penelitian Chen (2009) juga menunjukkan perlunya mempertimbangkan pengajaran ilmu pragmatik dalam kurikulum bahasa.

Dengan latar belakang inilah kita memahami bahwa ilmu pragmatik adalah ilmu yang nyata, dalam arti tidak hanya dapat di jelaskan melalui buku teks tetapi juga melalui media audio visual, juga di butuhkan intonasi, ekspresi wajah, bahasa tubuh dan sebagainya, maka peneliti menggunakan media film sebagai salah satu media dalam strategi pengajaran pragmatik di Indonesia.

Selama ini, banyak penelitian telah dilakukan untuk melihat tingkat efektifitas penggunaan film dalam meningkatkan keterampilan, mendengar (listening) dan berbicara (speaking). Namun sangat jarang penelitian yang dilakukan dalam materi serta metode pengajaran pragmatik. Karena kurangnya penelitian di bidang pengajaran pragmatik inilah, mendorong peneliti untuk menggali lebih dalam tentang efektifitas pengajaran pragmatik dalam hal ini melalui film, serta mendalami aspek-aspek dalam teori pragmatik seperti speech act, presuposition, deixies, cultural schema, cooperative principle, politeness serta aspek komunikasi non-verbal seperti bahasa tubuh, ekspresi wajah dan sebagainya.

Tetapi hasil beberapa penelitian tentang pengajaran pragmatik di Indonesia
(Nurdiana, 2012; Santi, 2010) menunjukkan hasil bahwasanya dalam pengajaran di kelas, kebanyakan para pengajar masih menggunakan strategi konvensional dan banyak memberi materi hanya dari sumber buku teks dan bermain peran (role play).

Dari fakta dan latar belakang yang dijelsakan di atas dapat disimpulkan betapa pentingnya kompetensi dalam belajar bahasa asing bagi para mahasiswa, sebagaimana Widiati dan Cahyono (2006) menegaskan, bahwa dalam meningkatkan keterampilan berbicara (speaking) sangat diperlukan kompetensi sociolinguistic (dalam hal ini termasuk dalam ranah kompetensi pragmatik), dengan memahami sisi sosial budaya sebuah masyarakat, seseorang yang sedang belajar bahasa asing akan mengerti tanggapan atau pernyataan apa yang sesuai dengan konteks dan latar budaya penutur aslinya.

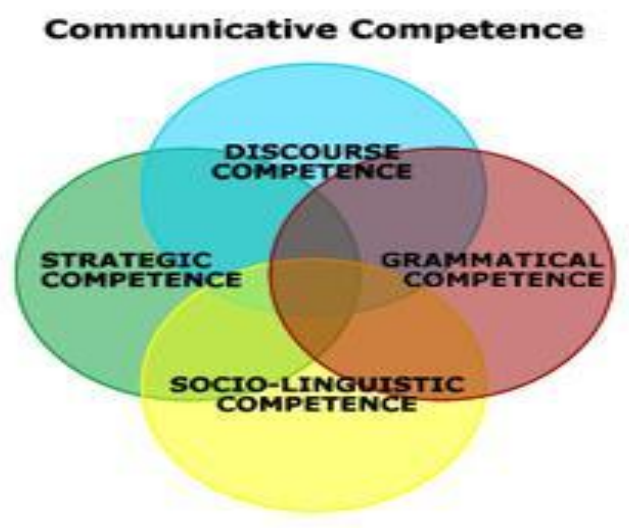

\section{(Theoritical framework of Communicative Competence / source : Canale and Swain, 1980 in Grossi, 2009, p. 6). \\ Keuntungan Menggunakan Media Film Dalam Pengajaran Pragmatik}

Media film merupakan salah satu materi otentik yang sering di gunakan sebagai media pembelajaran bahasa Inggris sebagai bahasa asing. Penggunaan materi otentik baik materi audio visual seperti film dapat menjadi materi tambahan yang menarik, karena mahasiswa akan belajar bahasa asing sesuai dengan yang digunakan oleh penutur aslinya.

Dengan memahami dialog yang terjadi dalam adegan-adegan film, diharapkan mahasiswa jurusan bahasa Inggris dapat memahami perbedaan makna kalimat antara bahasa Ibu 
mereka dalam hal ini bahasa Indonesia dan bahasa Inggris sebagai bahasa penutur asing asli, lebih luas lagi, mereka akan memahami komunikasi verbal dan non-verbal dari para penutur asli Bahasa Inggris.

Peacock (1997) dikutip dalam Salwa (2013) menyatakan bahwa penggunaan materi otentik seperti film akan meningkatkan motivasi belajar siswa karena lebih menarik dan juga karena dilengkapi oleh gambar, suara, serta banyak contoh budaya sehingga semakin meningkatkan minat pembelajar dalam mempelajari bahasa asing.

\section{METODE}

Metode yang digunakan dalam penelitian ini adalah experimental design dengan mengaplikasikan Nonrandomized Control Group, Pre-test-Post-test Design. Grup nonrandom di sini bermakna kelas yang tersedia. Pre-test dan post-test membantu dalam menentukan ada tidaknya perbedaan setelah diterapkan treatment. Subyek dalam penelitian ini adalah dua kelas mahasiswa semester lima / $\mathrm{V}$ program studi Bahasa Inggris Universitas Kanjuruhan Malang dengan jumlah participant sebanyak 20 orang mahasiswa (17 perempuan dan 3 laki-laki).Mereka adalah mahasiswa pada semester ini yang menempuh mata kuliah Pragmatik. Dua kelas yang menjadi subyek penelitian akan diambil secara acak.

Tes dalam bentuk tes tulis merupakan instrumen utama penelitian ini. Tes yang digunakan dalam penelitian ini ada dua macam: tes awal dan tes akhir. Tes awal digunakan untuk mengetahui kemampuan awal mahasiswa sebelum video diterapkan dalam pembelajaran Pragmatik, sedangkan tes akhir digunakan untuk mengetahui peningkatan kesadaran dan kompetensi pragmatik mahasiswa setelah strategi penggunaan video di implementasikan pada kelompok eksperimen. Data mayor (hasil tes siswa) dianalisa dengan menggunakan kalkulasi statistik SPSS dengan menggunakan analisis uji T, sedangkan data minor (hasil kuesioner dan interview) dianalisa guna memperkuat hasil data mayor.

\section{HASIL DAN PEMBAHASAN}

\section{Hasil Pre-Test}

Dari hasil pre-test kedua grup baik pada kontrol group maupun experimental group di ketahui hasil komputasi pada experimental group, $\mathrm{Xi}$ adalah 77,2 sedangkan s1 adalah 3,48 sedangkan pada kontrol grup, X2 adalah 76,7 sedangkan S2 sejumlah 5,55.

Perhitungan t-value dan DF (N1 + N2)-2 dapat dilihat dari tabel dibawah ini :

\begin{tabular}{|l|l|}
\hline Experimental Group & Control Group \\
\hline$N_{1}=20$ & $N_{2}=20$ \\
$\sum X_{1}=1544$ & $\sum X_{2}=1534$ \\
$\sum X_{1}{ }^{2}=119440$ & $\sum X_{2}{ }^{2}=118276$ \\
$\overline{X_{1}}=77,2$ & $\overline{X_{2}}=76,7$ \\
$S_{1}=3,48$ & $S_{2}=5,55$ \\
\hline
\end{tabular}

Dari perrhitungan di atas dapat diketahui bahwasanya hasil t-value adalah 0,333 dan hasil dari DF pada pre-test yang dilakukan pada experimental group adalah 38 .

\section{HASIL POST-TEST}

Setelah diadakan treatment pada experimental group dengan menggunakan media film, diadakan post-test dengan hasil $\mathrm{Xi}$ sejumlah 84,9 sedangkan $\mathrm{S} 1$ adalah 4,31, sedangkan pada kontrol grup didapatkan jumlah X2 : 78,45 dan S2 sejumlah 5,18.

\begin{tabular}{|ll|l|}
\hline \multicolumn{2}{|c|}{ Experimental Group } & \multicolumn{2}{l|}{ Control Group } \\
\hline$N_{1}=20$ & $N_{2}=20$ \\
$\sum X_{1}=1698$ & $\sum X_{2}=1569$ \\
$\sum X_{1}{ }^{2}=144532$ & $\sum X_{2}{ }^{2}=123625$ \\
$\bar{X}_{1}$ & $=84,5$ & $\bar{X}_{2}=78,45$ \\
$S_{1}$ & $=4,31$ & $S_{2}=5,18$ \\
\end{tabular}

Dari perhitungan di atas dapat diketahui bahwasanya hasil t-value adalah 3,92 dan hasil dari DF pada post-test yang dilakukan pada experimental group adalah 38 .

Dengan jumlah DF 38, maka t-kritis yang diambil adalah $1 \%$ dan $5 \%$

Maka : t-kritis pada derajat signifikansi 5\% : 2.201

t-kritis pada derajat signifikansi $1 \% \quad: 2.704$ 
Maka hasil pretest : $2.201>0.33<2.704$

Hasil post-test : $2.201,3,92>2.704$

Dengan hasil yang demikian, maka ada peningkatakn signifikan dalam hasil kemampuan siswa setelah implementasi video sehingga dapat disimpulkan bahwasanya research hypothesis (HI) yang menyatakan bahwa ada perbedaan dalam tingkat kompetensi mahasiswa yang diberikan treatment film dan tidak diberikan treatment adalah benar.

\section{HASIL INSTRUMEN PENDUKUNG}

Hal tersebut juga didukung oleh hasil observasi di kelas pada saat treatmenttreatment yang dilaksanakan dapat diamati adanya antusiasme para mahasiswa di experimental group dalam mempelejarai ilmu pragmatik melalui media film.

Dalam penelitian ini, peneliti juga menggunakan kuesioner sebagai instrumen sekunder untuk mendukung data mayor. Kuesioner ini berisi 5 item di mana pernyataan pertama bahwa media film lebih menarikuntuk digunakan sebagai media pembelajaran disepakati oleh 18 responded. Lebih dari itu semua responden kami sepakat bahwa media film memang membuat mahasiswa lebih faham tindak tutur sesuai dengan penutur asli, dan mereka semua juga berpendapat bahwa metode ceramah dalam belajar ilmu pragmatik cepat membuat mereka bosan. Disamping itu, 17 responden setuju bahwa teori-teori pragmatik akan mudah dipahami dengan bantuan media film dibanding hanya dengan metode ceramah/konvensional atau hanya dengan menggunakan buku ajar saja.

Peneliti juga mengadakan wawancara secara langsung kepada para participant experimental group untuk lebih mengetahui sejauh mana keefektifitasan penggunaan film dalam pengajaran pragmatik. Berdasarkan hasil interview dapat ditarik kesimpulan bahwa para participan memberi respon positif terhadap penggunaan media film dalam pengajaran ilmu pragmatik dikarenakan penggunaan bahasa didalam film adalah langsung dari para penggunanya (native speakers) sehingga akan membuat para partisipan semakin mengerti fungsi tindak tutur berdasarkan konteks serta budaya yang melatarbelakangi para pengguna bahasa tersebut.

\section{PEMBAHASAN}

Dari hasil temuan di atas, ada beberapa hal yang menarik untuk dibahas, pertama, bahwa film yang digunakan untuk ilmu pragmatik dapat berasal dari beberapa jenis genre yang berbeda, dalam penelitian ini peneliti menggunakan film kartun, drama, action, dan juga komedi yaitu antara lain film-film berjudul 'Titanic', 'Mirror-Mirror'.

Berbagai jenis genre film ini terbukti meningkatkan pemahaman mahasiswa dalam mempelajari ilmu pragmatik, hal ini sesuai dengan pernyataan Huang (2009) yang menyatakan bahwa genre film berpengaruh dalam pemahaman teori-teori ilmu pragmatik khususnya dalam mempelajari bahasa verbal dan non-verbal seperti ekspresi wajah serta gesture (bahasa tubuh).

Kedua, subtitle atau terjemahan film yang digunakan dalam mengajar film sebaiknya adalah bahasa asli bahasa tersebut (dalam hal ini adalah bahasa Inggris) atau dapat juga menggunakan film berbahasa Inggris tanpa adanya subtitle atau terjemahan Bahasa Indonesia.

Dengan semakin meningkatkan kompetensi pragmatik mahasiswa maka secara otomatis juga akan meningkatkan communicative competence (kemampuan komunikasi) mahasiswa dikarenajab salah satu faktor terpenting dalam pembelajarn berbasiskan komunikatif adalah fokus pada arti ( meaning) dan bukan pada bentuk (form). Dalam hal ini pengajaran dengan menggunakan media film sebagai media otentik mempunyai fokus pada arti dalam konteks (meaning) dan bukan pada bentuk (form).

\section{KESIMPULAN DAN SARAN}

Dari hasil penelitian ini dapat disimpulkan bahwasanya penggunaan media film dapat meningkatkan kompetensi pragmatik para mahasiswa Prodi Pendidikan Bahasa Inggris Universitas Kanjuruhan Malang dikarenakan belajar dengan menggunakan media audio visual, yang salah satunya adalah dengan menggunakan media film akan dapat meningkatkan motivasi belajar para mahasiswa dimana mereka akan lebih dapat memahami speech acts (tindak tutur) sesuai dengan 
budaya para penutur asli bahasa tersebut dibanding dengan metode konvensional atau hanya dengan mendengarkan ceramah (lecturing).

Diharapkan hasil penelitian ini dapat mengembangkan ilmu serta pengayaan bahan ajar bagi para pengajar ilmu pragmatik serta untuk para peneliti selanjutnya agarat mengembangkan peneitian ini dalam bentuk genre film atau instrument yang berbeda sehingga akan semakin memperkaya strategi atau metode yang efektif dalam pengajaran ilmu pragmatik.

\section{SARAN}

Bagi para peneliti selanjutnya diharapkan agar dapat memperluas genre yang digunakan seperti pembelajaran pragmatik dengan media drama, talk show, dsb. Alternatif lain juga film dapat diaplikasikan sebagai materi tambahan ( supplementary materials) dalam pengajaran ilmu Semantics, Morphology, dan bidangbidang linguistics yang lain.

Bagi para guru diharapkan agar lebih memperhatikan tehnik dan media dalam mengajar ilmu pragmatik agar ilmu ini dapat dengan mudah diserap dikarenakan pragmatik dianggap ilmu yang sulit dan juga mengingat fungsi Bahasa Inggris di Indonesia adalah sebagai bahasa asing dimana bahasa asing tersebut tidak digunakan dalam komunikasi sehari-hari, maka penerapan ilmu pragmatik akan lebih mudah dilakukan dengan cara penambahan materi otentik berupa film-film yang dapat menggambarkan bagaimana para penutur asli menggunakan bahasa mereka dalam kehidupan sehari-hari.

Terakhir, bagi para mahasiswa diharapkan agar lebih mandiri dan lebih leluasa untuk meningkatkan kompetensi pragmatik mereka dengan menonton film-film yang bisa dijadikan analisa untuk memahami konsepkonsep pragmatik kendati hal ini tidak dilakukan didalam kelas sehingga secara tidak langsung hal ini akan dapat meningkatkan kemampuan belajar mahasiswa secara mandiri ( autonomous learning).

\section{DAFTAR PUSTAKA}

Brock, M and Nagasaka, Y. 2005. Teaching Pragmatics in the EFL Classroom? Sure You Can !. TESL Reporter. 38 (1).pp. 17-26.

Chen,Y.2009. Learner Perceptions of Instructions in L2 Pragmatics. English Language Teaching. (2) 4.pp. 154 158.

Grossi. 2009. Teaching Pragmatic Competence : Compliments and Compliment responses in the ESL classroom. Educational journal, vol (24) 2.Pp. 53 61.

Huang, H .2009. Applogies in Film : Implications for Language Teaching. St John's and St.Marys Institute of Technology. (1).1.

Nurdiana.2012. Raising Pragmatic awareness: how to raise conversational implicature through movies. Journal of English language and Culture. (2).2.

Soler, E.A.2008. Investigating Pragmatic Language learning in Foreign Language Classrooms. International Review of Applied Linguistics in Language Teaching. (46).3. pp. 173-178.

Salwa .2013 .The Importance of using authentic materials in increasing EFL learners' motivation. Dalam Cahyono dan Megawati ( 2013). Materials and Media in English Language Teaching. State University of Malang Press. Malang.

Santi, V.N.2010 . EFL Teachers' Perception and Production of Requests.Unpublished Graduate Thesis. State University of Malang Press . Malang.

Toyyibah.2012. Pragmatic Competence of Indonesian EFL Learners. DalamCahyono, B.Y dan Indah, R.N ( 2012). Second Language Research and Pedagogy.State University of Malang Press. Malang.

Widiati, U danCahyono, B.Y .2006. The Teaching of EFL speaking in the Indonesian context : The State of Art. Bahasa dan Seni. (34).2. pp. 269 - 277. 